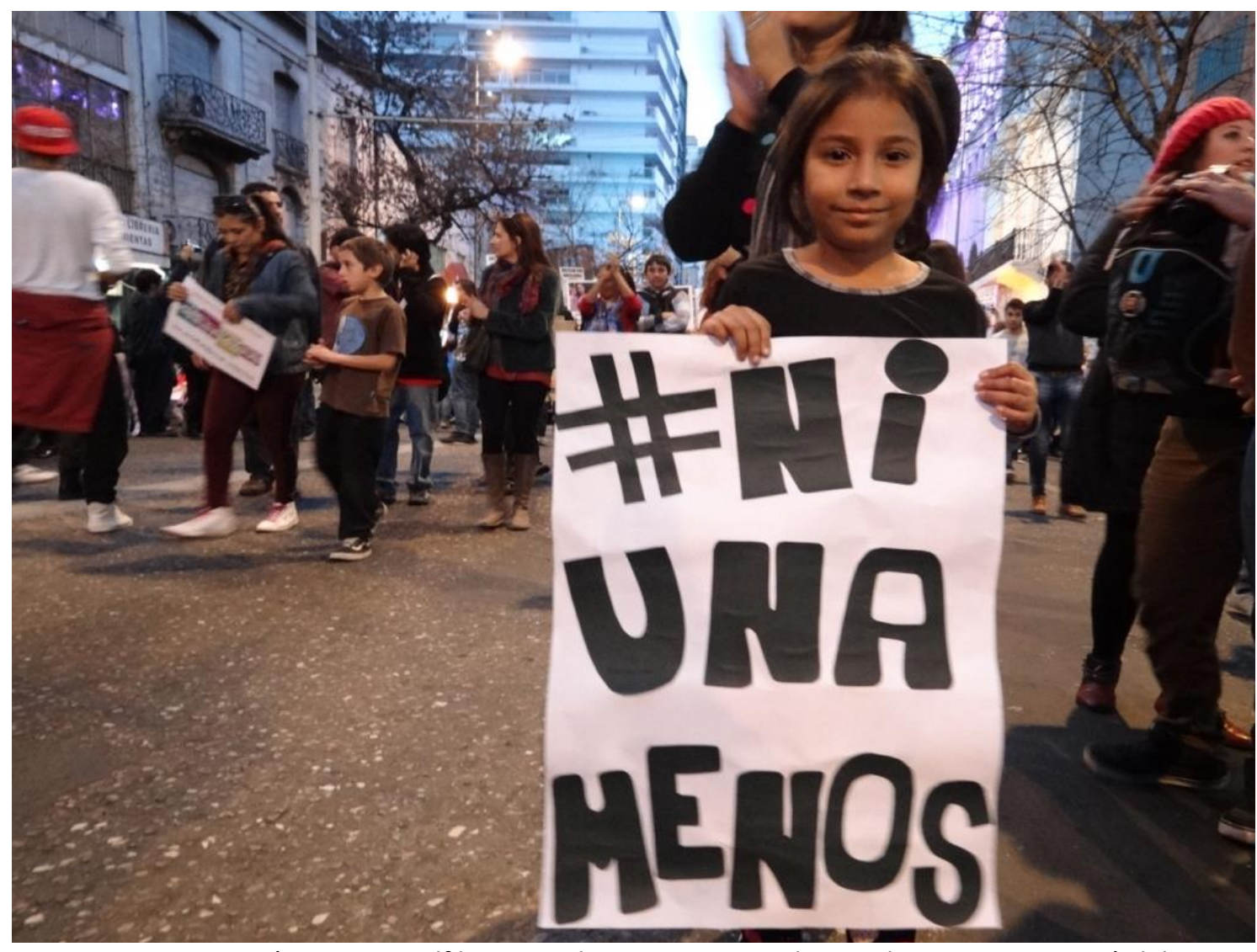

FOTOS: Irina Morán - Revista Alfilo - Periodista Feminista. Militante de Ni Una Menos Córdoba y Mujeres por un parto Respetado 


\title{
EDUCACIÓN Y GÉNERO EN EL ESPACIO SOCIAL CORDOBÉS. UNA APROXIMACIÓN A LA ESTRUCTURA DE LA DESIGUALDAD SOCIAL
}

\author{
Cecilia Ines Jimenez ${ }^{1}$
}

\begin{abstract}
Resumen: El papel que el género juega en la construcción de las clases sociales viene siendo cada vez más atendido en el campo de estudios sobre desigualdad social. Los trabajos clásicos sobre la estratificación han tendido a olvidar esta variable, o bien a subsumirla en la posición del principal sostén de hogar, que suele corresponder con un varón. El avance durante el siglo XX de las mujeres en el acceso a derechos se ha plasmado en su creciente y constante incorporación al mercado de trabajo y al sistema educativo, sobrepasando en algunos casos las titulaciones o niveles educativos de los varones. Considerando el lugar creciente del capital cultural en la definición de las posiciones de clase, y atendiendo al aumento de inversiones de las mujeres en esta materia, proponemos una lectura de la distribución del capital cultural en las diferentes clases sociales de Gran Córdoba (2011) por género. Además, realizamos una interpretación en términos de homogamia educativa entre cónyuges. Por último, esbozamos algunas hipótesis sobre el rol de las credenciales educativas para definir la posición de las mujeres al interior de los hogares, como referentes de hogar - ya sea en situaciones conyugales o monoparentales - o como cónyuges en las diferentes clases sociales.
\end{abstract}

Palabras clave: Capital cultural. Estrategias de reproducción social. Clases sociales.

\section{EDUCAÇÃO E GÊNERO NO ESPAÇO SOCIAL CORDOBÊS. UMA APROXIMAÇÃO À ESTRUTURA DA DESIGUALDADE SOCIAL}

Resumo O papel que o gênero desempenha na construção das classes sociais vem sendo cada vez mais abordado no campo de estudos sobre desigualdade social. Os trabalhos clássicos sobre a estratificação tenderam a ignorar essa variável ou restringi-la à posição do principal responsável pelo sustento da casa, geralmente um homem. O avanço das mulheres ao longo do século XX no tocante ao acesso a direitos se refletiu em sua crescente e constante incorporação ao mercado de trabalho e ao sistema educacional, superando em alguns casos os títulos ou níveis de formação dos homens. Considerando a crescente influência do capital cultural na definição das posições de classe e atendendo ao aumento dos investimentos das mulheres nessa matéria, propomos uma leitura da distribuição do capital cultural nas diferentes classes sociais da Grande Córdoba (2011) por gênero. Além disso, realizamos uma interpretação em termos de homogamia educacional entre cônjuges. Finalmente, esboçamos algumas hipóteses sobre o papel das credenciais educacionais para definir a posição das mulheres no interior dos lares, como referências da casa — seja em situações conjugais ou monoparentais — ou como cônjuges nas diferentes classes sociais.

Palavras-chave: Capital cultural. Estratégias de reprodução social. Classes sociais.

\section{EDUCATION AND GENDER IN CORDOBA'S SOCIAL SPACE. AN APPROACH TO THE STRUCTURE OF SOCIAL INEQUALITY}

\begin{abstract}
The role that gender plays in the construction of social classes has been receiving increased attention in the field of studies on social inequality. Classical works on stratification have tended either to neglect this variable altogether or to take it as subordinate to the position of the head of the household, which is usually a male. During the twentieth century, women's progressive access to rights has been reflected in their growing and constant incorporation into the labor market and the educational system, exceeding in some cases the qualifications or educational levels of men. Taking into account the increasing significance that cultural capital has won in the determination of class positions, and focusing in the growth of women's investments in that resource, we present a mapping of the distribution of cultural capital by gender in the different social classes of Gran Córdoba (2011). In addition, we advance some considerations regarding educative homogamy between spouses. Finally, we sketch some hypotheses concerning the role that cultural capital plays in defining women's positions within households, as heads of the household (in conjugal or simple-parental situation) or as spouses, in different social classes.
\end{abstract}

Key words: Cultural capital. Strategies of social reproduction. Social classes.

${ }^{1}$ Investigadora Adjunta de Conicet, Instituto de Humanidades. 


\section{INTRODUCCIÓN}

En el terreno de estudios sobre la estratificación social es polémico el rol que se asigna a la inserción ocupacional de las mujeres para posicionarlas socialmente, así como la incidencia que tiene esta inserción sobre sus hogares, cuando éstos se conforman por pareja de miembros heterosexuales ${ }^{2}$. Desde algunos consensos asentados en esta materia, se convino en aproximarse a mediciones de las clases sociales a partir de la estructura ocupacional del varón, asignando a la mujer la misma posición social que la del jefe de hogar (Crompton, 1997). Si bien esto da cuenta de la desigual división del trabajo al interior de los hogares entre trabajo productivo y reproductivo - reconociendo la posición subordinada de las mujeres -, también colabora en invisibilizar los aportes que hacen las mujeres para el posicionamiento de los hogares en la distribución de recursos. Así, autores como Goldthorpe ${ }^{3}$, o bien las excluye de los diseños muestrales, o bien las analiza por separado (Jorrat, 2008). Como han señalado Bertaux y Thompson (2009) los estudios de estratificación y movilidad social presentan una serie de limitaciones, que es preciso considerar desde abordajes tanto cuantitativos como cualitativos. En primer lugar, el individualismo metodológico, que no considera los contextos familiares donde el sujeto entrevistado es producido (más allá de la ocupación paterna) y donde adquiere sus características y competencias sociales (no solo recursos económicos, sino también culturales, relacionales, energía moral y psíquica). En segundo lugar, la consideración de las mujeres solo como trabajadoras, sin atender a otros repertorios de acción (como esposas, hermanas, madres, tías, abuelas, etc.). Desde estos papeles las mujeres también influyen en la vida familiar y en los posicionamientos sociales. Por último, al considerarse en las muestras sobre movilidad y estratificación social sólo la ocupación masculina - que los autores consideran una "chaqueta" demasiado estrecha - se pierde riqueza analítica y contextual (Bertaux y Thompson, 2009).

Con intención de incorporar una perspectiva de género a los estudios de movilidad social, y no tan solo de añadir el género como una variable, algunos trabajos

\footnotetext{
${ }^{2}$ Sin desconocer la diversidad incluida en la noción de género, en este artículo la hacemos equivalente a la de sexo, al contar con una muestra que no incorpora diferentes manifestaciones de esta variable (EPH INDEC). No obstante, en el trabajo cualitativo, relevamos el caso de un hogar con pareja homosexual masculina.

${ }^{3}$ Goldthorpe es uno de los autores de referencia a nivel internacional en estudios de movilidad y estructura social, y sus modelos de análisis son replicados en diferentes países para realizar estudios comparativos.
} 
comienzan a complejizar la mirada sobre estos procesos. Así, para apartarse de la habitual perspectiva individualista que considera solo la ocupación del jefe de hogar -e imputa la clase resultante a los demás miembros del hogar -, se desplaza el enfoque de la unidad de análisis del trabajador a una que contemple las inserciones de ambos miembros de la pareja ${ }^{4}$ (Jorrat, 2008; Bertaux y Thompson, 2009). Como sugieren Gómez-Rojas y Riveiro (2014) centrarse solo en la ocupación principal del padre presupone algunos sesgos 5 : la existencia de familias nucleares con ambos padres conviviendo en el hogar; la exclusión muestral de personas que no cuentan con esas características (como los orígenes sociales de las personas que se crían en contextos de familia ampliada o en otras instituciones), que, a su vez presupone un sesgo normativo (tipo de familia heterosexual y con división de roles y funciones).

Otro de los tópicos que anudan esta discusión se centra en la mayor o menor homogeneidad de los miembros de un hogar en cuanto a sus orígenes de clase social. Maceira (2018) problematiza también los análisis convencionales de la estratificación social, al suponer homogeneidad en los hogares a partir de la posición del referente de hogar, sin contar la contribución de cónyuge (que suele ser mujer). Anteriormente señalamos que esta operación desestima el aporte de la mujer a la caracterización del hogar, así como en la acumulación de capitales que se transmiten en las familias (Bertaux y Thompson, 2009).

Este artículo pretende comenzar a arrojar luz sobre esta cuestión, desde un estudio que utiliza metodologías cuantitativa y cualitativa, en el que se examinan los niveles educativos alcanzados por hombres y mujeres (referentes de hogar y cónyuges; referentes de hogares monoparentales o unipersonales) de las diferentes clases sociales de Gran Córdoba (2011), hipotetizando qué papel cumplen las acumulaciones del capital cultural en la definición de esas posiciones dentro y fuera de los hogares.

\section{EL CAPITAL CULTURAL EN EL MERCADO DE TRABAJO... ¿Y EN EL MERCADO MATRIMONIAL?}

Durante el siglo XX, las transformaciones económicas y las dinámicas demográficas generaron variedad de cambios en las familias, lo que favoreció la salida

\footnotetext{
${ }^{4}$ Consultar Gómez-Rojo (2008) acerca de cómo incluir a las mujeres con ocupación que forman parejas con hombres en la imputación de las clases sociales.

${ }^{5}$ Los estudios de movilidad social sobre los que reflexionan estos autores se apoyan en una comparación de las posiciones de origen (ocupación del padre del encuestado cuando éste tenía 16 años) y las del destino (la del propio entrevistado; Gómez-Rojas y Riveiro, 2014).
} 
de la mujer al mercado de trabajo y propició un nuevo papel social femenino con nuevos derechos y deberes (Conde, 1982). En ese contexto, el progresivo incremento del capital escolar fue modificando las estrategias de reproducción de las familias y las posibilidades de autonomía de las mujeres (Jiménez Zunino y Roquero García, 2016).

Como viene siendo trabajado por diferentes autoras para el contexto europeo (Crompton, 1997; Salido Cortés, 2001) el aumento de la participación femenina en el mercado de trabajo hace difícil sostener la exclusión de las mujeres en los estudios de estructura social ${ }^{6}$. A lo que se suma el creciente predominio del capital escolar - en cuyas acumulaciones las mujeres se han mostrado muy eficaces - en las estrategias de reproducción social, si bien iniciado en las clases medias cultivadas, llega ahora también a la clase trabajadora y baja (Terrail, 1984; Bourdieu, 1998; Carabaña, 1993; Jurado, 2005).

Argentina ha seguido dinámicas similares a las europeas, tanto en la evolución del empleo femenino como en la creciente inserción de las mujeres al sistema educativo. En efecto, las mujeres han aumentado su participación en el mercado de trabajo, aunque con pautas de incorporación diferentes según estratos sociales. Un análisis de Torrado muestra que las mujeres de los estratos medios asalariados (profesionales y técnicos), junto con las del estrato marginal, cuentan con los niveles más altos de participación laboral. En contraparte, las mujeres de los estratos autónomo y obrero asalariado tienen menor participación. Otras diferencias se observan en los ritmos de incorporación: así, mientras las primeras se insertan más tardíamente y participan en edades centrales con gran intensidad; las del estrato autónomo comparten estas características, pero con menor participación. Las mujeres de estrato obrero, por su parte, tienen máxima participación a edades tempranas (20-24 años) y luego se retiran - coincidiendo con el ciclo de reproducción - para reincorporarse a partir de los 60 años levemente. Por último, las mujeres de estrato marginal comienzan a trabajar precozmente - principalmente en servicio doméstico - y tienen tasas en aumento hasta los 60-64 años (Torrado, 2003, pp. 219-220).

Por otra parte, crecientemente las mujeres se incorporaron al sistema educativo, superando la participación de los hombres en años recientes. Si hacia 1930 varones y mujeres estaban equiparados en analfabetismo, entre 1930 y 1950 se aceleró el

\footnotetext{
${ }^{6}$ Sin perder de vista que las mujeres se insertan en mercados de trabajo segmentados, que tienden a recluirlas históricamente en ciertos nichos de actividad, con "techos de cristal" en sus carreras, todo lo cual dificulta aplicar el mismo patrón de medida de las posiciones ocupacionales que se usa para los varones (Crompton, 1997; Salido Cortés, 2001).
} 
crecimiento de la matrícula secundaria femenina - respecto a la masculina -, y a partir de 1950 las mujeres comenzaron a avanzar en matrícula universitaria (Torrado, 2003) ${ }^{7}$. En efecto, desde 1960 las mujeres ingresan masivamente a la universidad, especialmente las que provenían de las clases medias urbanas. Sin embargo, poco a poco fueron incorporándose también desde sectores populares y clases medias bajas y obreras, gracias a la gratuidad de la enseñanza (a mediados de 1960, el 30\% de los egresados eran mujeres; Barrancos, 2012).

Considerando estas dinámicas en materia laboral y educativa, es pertinente preguntarse acerca del posicionamiento de las mujeres cónyuges que son asignadas a una clase social por la ocupación masculina. Una forma en que se ha explorado el "aporte" de clase de los miembros de la pareja es a través de los estudios sobre homogamia matrimonial (Carabaña, 1994). De acuerdo con el relevamiento de la Encuesta Nacional sobre Estructura Social - PISAC (2014-2015), la homogamia representa el $41 \%$ de las parejas activas de toda la estructura social argentina. El resto está conformado por personas de diferentes $\operatorname{clases}^{8}$, lo que da la pauta de cierta heterogeneidad en la composición de los miembros de la pareja en el mercado matrimonial $^{9}$ (Maceira, 2018).

Tomando en cuenta los niveles educativos alcanzados por los miembros de la pareja - considerada como una de las variables que definen las clases sociales Binstock (2009) sugiere homogamia educativa para toda la población, al margen de estar unidos legal o consensualmente. Sin embargo, algunos resultados del estudio de Rodríguez (2011, p. 72) señalan que las mujeres duplican a varones en porcentaje de estudios terciarios completos (15 años de instrucción), mientras que en los estudios universitarios completos (18 años de instrucción) los varones se encuentran levemente por encima. Asimismo, según este autor las mujeres tienden a unirse a parejas de menor nivel de instrucción. En suma, "la reducción de las diferencias educacionales -

\footnotetext{
${ }^{7}$ Hay que considerar que hasta 1960 el magisterio formaba parte del nivel medio, y las mujeres eran alentadas a hacerlo. Luego se fueron orientando a bachillerato y la opción comercial, que proporcionaban sendas vías: educación superior y ocupaciones en administración y comercio (Torrado, 2003).

${ }^{8}$ Entre las posibilidades más frecuentes de heterogamia, Maceira destaca: 1) uniones entre sostén de hogar en posiciones burguesas y cónyuge asalariado altamente calificado; 2) uniones entre sostén de hogar asalariado altamente calificado y cónyuge en clase trabajadora formal; 3) uniones entre sostén de hogar de pequeña burguesía y cónyuge inserto en proletariado informal; 4) uniones entre sostén de hogar de clase trabajadora formal y cónyuges informales (Maceira, 2018: 60-61).

9 Según Torrado, el mercado matrimonial opera en analogía a un mercado "al que hombres y mujeres concurren como oferentes y demandantes (...). Se trata de un mercado fragmentado por clivajes relacionados con la edad, la etnia, la religión, la clase social, la cultura, el nivel educativo, la localización residencial, etc." (Torrado, 2007: 400).
} 
vinculadas a logros de las mujeres en el sistema educativo - hace que las uniones en las cuales la mujer tenga un nivel de instrucción inferior al varón sean cada vez menos frecuentes" (Rodríguez, 2011: 80). En un contexto de expansión de la matrícula educativa, que favoreció más a las mujeres (García de Fanelli, 2005) la tradicional tendencia a la hipergamia femenina comienza a perder vigencia, surgiendo formas más equivalentes en algunas clases sociales, y con hipogamia femenina en otras ${ }^{10}$.

Por otra parte, los procesos de la llamada desinstitucionalización de las familias nucleares (Meil, 1999), se han plasmado en el aumento de hogares que cuentan con jefatura femenina ${ }^{11}$. En las últimas tres décadas esta figura ha aumentado (de 22 a 34\%) especialmente en hogares de pareja con hijos: pasó del 2 al 12\% (Binstock, 2018: 423). Sin embargo, en la estructura total de los hogares sigue teniendo un peso importante la figura de los nucleares completos $(38 \%) \mathrm{y}$, de los que tienen jefatura masculina, un $52 \%$ está al mando de este tipo de hogares. En tanto, los que tienen jefatura femenina son mayormente unipersonales $(28 \%)$ o nucleares incompletos monoparentales $(27,4 \%$; Binstock, 2018: 429). Considerando las diferentes clases sociales, más de la mitad de los hogares con jefatura femenina se concentran en la clase media $(50,6 \%)$, poco menos en la clase obrera $(46,1 \%)$ y solo un $0,7 \%$ en la clase alta (Perona y Schiavoni, 2018: 476). Estos datos son coherentes con los hallados en nuestra investigación, como veremos en siguientes apartados.

En suma, el avance de las mujeres en la participación en el mercado de trabajo y en el acceso a cada vez más elevados niveles de educación, confluye con formatos menos rígidos de organización familiar que pueden generar intersticios de autonomía que disputan la unicidad del modelo de varón proveedor y jefe de familia. En los siguientes apartados analizaremos el modo en que incide el género en la conformación de las clases sociales cordobesas, atendiendo al papel que puede jugar el capital cultural. Específicamente, nos centraremos en las diferencias por sexo y posición (referente de hogar o cónyuge) al interior de las familias. Asimismo, atenderemos al modo en que se insertan en el mercado laboral y cómo se articulan esas inserciones en la configuración de los hogares.

\footnotetext{
${ }^{10}$ Hipergamia es el casamiento de una mujer con alguien de mayor nivel de estudios, mientras que la hipogamia es la tendencia contraria (Rodríguez, 2011).

11 Por una cuestión estilística, haremos equivalentes a lo largo del texto los términos: jefe de hogar, principal sostén de hogar y referente de hogar. Aunque somos conscientes de que el término "jefatura de hogar" es menos preciso, pues responde a una designación realizada al momento de la encuesta, y que puede involucrar aspectos como la toma las decisiones o el mayor aportante de dinero; Binstock, 2018).
} 


\section{HERRAMIENTAS METODOLÓGICAS}

Para caracterizar a las clases sociales cordobesas nos apoyamos en dos investigaciones que comparten enfoque epistemológico relacional y combinan metodología cuantitativa y cualitativa: una colectiva sobre clases sociales y otra individual sobre clases medias en la ciudad de Córdoba ${ }^{12}$. La fuente de datos es la EPH 2003 y 2011 de INDEC.

La construcción relacional del espacio de clases sociales se apoya en la consideración de un conjunto de variables que se asocian simultáneamente, que son analizadas con métodos multivariados ${ }^{13}$. Estos métodos son pertinentes para ordenar los datos y construir hipótesis, tipologías e interpretaciones de manera exploratoria (LópezRoldán, 1996; Baranger, 2004), porque dan una aproximación a la desigualdad en términos de los efectos estructurales del sistema de relaciones entre las variables y sus respectivas modalidades. Este procedimiento se complementó con técnicas de clasificación (Clasificación Jerárquica Ascendente) que posibilitan distinguir clases recortadas, en el papel, en un espacio multidimensional (Gutiérrez y Mansilla, 2015). Uno de los hallazgos de esta investigación colectiva fue la incidencia del género para definir fracciones de algunas de las principales clases sociales, aunque no en todas, como veremos.

A continuación, se detallan algunas características de las clases sociales que emergen de la construcción de cuatro clases teóricas, desde las asociaciones significativas de algunas variables. En algunas clases, el procedimiento de clasificación particionó fracciones de clase con significación sociológica, que se detallan en el apartado siguiente. Complementariamente, se realizaron entrevistas en profundidad a 43 referentes de hogar ${ }^{14}$, configurando una muestra representativa por cada clase y fracción de clase (cuadro 1), a quienes se preguntó acerca de una amplia variedad de prácticas, sentidos y recursos (estrategias habitacionales, educativas, laborales, de

\footnotetext{
12 Proyecto colectivo: "Reproducción social en el Gran Córdoba: estrategias familiares y dinámicas recientes" (Investigadora responsable: Alicia Beatriz Gutiérrez, PICT 2016-2018), e individual: "La transformación de las clases sociales en Córdoba. Estrategias de reproducción social en las trayectorias de las clases medias".

${ }^{13}$ Las variables consideradas fueron: sexo y edad del referente de hogar, nivel educativo, calificación ocupacional, jerarquía ocupacional, tecnología ocupacional, ingreso (individual y familiar), tamaño del establecimiento, rama de actividad, cantidad de miembros del hogar por ambiente exclusivo.

${ }^{14}$ En algunas ocasiones ( 3 casos), la entrevista se aplicó a cónyuge, por no ser posible coordinar con el referente. En todos los casos los cuestionarios solicitaban información sobre ambos miembros de la pareja, sobre sus antecesores (padres y suegros), laterales (hermanos y cuñados) y descendientes (hijos).
} 
sociabilidad, de organización doméstica y de consumos tecnológicos) que, en conjunto, configuran las estrategias de reproducción social de las diferentes clases sociales (Bourdieu, 2011). En este artículo nos centramos en el análisis de la distribución del capital cultural en las diferentes clases, para comprender el modo en que se estructura en las familias de Gran Córdoba, atendiendo a recuperar las diferencias por sexo y posición (referente de hogar o cónyuge) al interior de las familias. Además, para caracterizar mejor las diferentes clases, hemos seleccionado partes del material cualitativo que iluminan algunas interpretaciones sobre las "utilidades" del capital cultural al interior de los hogares.

\section{RESULTADOS Y DISCUSIÓN}

En una primera etapa de la investigación, hemos observado que, en todas las clases del espacio social de Gran Córdoba, aumentaron los niveles educativos entre 2003 y 2011 (Jiménez Zunino y Giovine, 2016). Analizando por composición los hogares de parejas convivientes, el nivel educativo de los cónyuges se corresponde grosso modo con el de los referentes, lo que daría cuenta de cierta homogamia en términos educativos, en sintonía con algunos de los antecedentes citados más arriba.

A tenor de los cambios recientes en el terreno educativo, se generaliza para todas las clases - con importantes diferencias por la segmentación y heterogeneidad del sistema - un modo de reproducción escolar (Mauger, 2013). En efecto, la educación constituye una inversión importante para las familias argentinas, y esto puede observarse atendiendo a la alta proporción de niños, adolescentes y jóvenes que asisten a algún establecimiento escolar. De acuerdo con el relevamiento realizado por la ENESPISAC (2014-2015), los porcentajes de asistencia a algún establecimiento educativo son del 98,3\% para alumnos de entre los 5 y los 12 años; del 86,9\% entre los 13 y los 18 años; del $37 \%$ entre los 19 y 26 años y del 6,6\% entre los de 27 años o más (Perona y Schiavoni, 2018: 488). En Córdoba también hemos observado una tendencia al incremento de asistencia a establecimientos escolares para los mismos grupos etarios, entre 2003 y 2011 (Jiménez Zunino y Giovine, 2016). El cambio más significativo se registra en la mayor participación de la clase baja en la escuela secundaria (la asistencia pasó del $25 \%$ al $11 \%$ en ese periodo), que podría ser resultado de la aplicación de 
políticas como la $\mathrm{AUH}^{15}$ (Álvarez, 2013).

Esto da importantes indicios acerca de las estrategias de reproducción sobre los hijos, algo en lo que aquí no podemos profundizar, pero que involucra estrategias complejas de organización doméstica. También comparando los niveles educativos alcanzados por los referentes de hogar con los de la generación anterior, los primeros han aventajado en niveles educativos a sus padres, fruto de la expansión general del sistema educativo en las últimas cuatro décadas.

\section{ELITE (CLASE ALTA)}

A pesar de las dificultades de medición de este grupo (Benza y Heredia, 2012 ${ }^{16}$ ), desde el conjunto de variables utilizadas en el análisis hemos podido identificar como perteneciente a la misma a un $17 \%$ de los hogares, que se asocian a ingresos altos $\left(10^{\circ}\right.$ decil), referente con calificaciones ocupacionales profesionales, en puestos directivos, patrones o propietarios. Esta clase está fuertemente masculinizada: las dos fracciones identificadas presentan asociación fuerte con referentes varones. Una de las fracciones (13\% de hogares) cuenta con un elevado capital cultural y ocupaciones asalariadas en categoría profesional en el Estado (enseñanza y cargos directivos); en tanto la otra, tiene fuerte relación con propiedad de empresas, y sus referentes se ocupan en cargos de dirección en ramas de servicios privados (Gutiérrez y Mansilla, 2015).

En el trabajo cualitativo, no obstante, intentamos buscar una representación equilibrada por género, y entrevistamos a mujeres también de esta clase social (ver cuadro 1). De los seis entrevistados de la $1^{\circ}$ fracción de la elite, la mitad son mujeres referentes de hogar, ocupadas en altos cargos de la administración estatal (poder judicial, instituciones educativas, etc.) y con elevadas credenciales educativas (posgrados). Algunas son referentes de hogar sin cónyuge (separadas o solteras), lo que puede sugerir que sus carreras profesionales han exigido renunciar a algunos roles tradicionales de género. En el caso de Silvana, camarista del poder judicial, posiblemente la condición de referente de hogar deviene de la situación de jubilado de

\footnotetext{
15 Asignación Universal por Hijo para la Protección Social (AUH): se trata de una política de transferencia de ingresos implementada por Decreto 1602/2009, y que alcanza específicamente a población de hogares cuyos padres están desocupados o en condiciones de informalidad.

${ }^{16}$ De acuerdo con estas autoras, el estrato alto en el año 2010 contaba con hogares reducidos en cantidad de miembros, menores tasas de dependencia, mayor cantidad de proveedores ( $78 \%$ con ambos cónyuges insertos en la esfera laboral, frente al 51\% del estrato bajo), edades comprendidas entre los 50-69 años, coincidentes con una fase madura de la trayectoria laboral, títulos superiores (62\% frente al $28 \%$ y $10 \%$ de los estratos medios y bajo, respectivamente; Benza y Heredia, 2012).
} 
su esposo, quien se ha desempeñado como contador de una empresa familiar, en la que ahora se desempeña el hijo mediano (licenciado en economía, con maestría en Gestión de Negocios y estancias formativas en el extranjero).

En la segunda fracción, más rica relativamente en capital económico, entrevistamos a dos empresarios importantes de Córdoba, que han utilizado también capital cultural para lograr esas posiciones. Ambos se encuentran en su segundo matrimonio actualmente, con cónyuges profesionales (licenciada en relaciones institucionales y odontóloga, respectivamente). No pueden establecerse reglas generales sobre la acumulación de capital cultural, pues la actividad en la que se desempeñan implica sus lógicas propias: la empresa de consultoría y marketing de Mariano está vinculada al circuito de conocimiento de las universidades, públicas y privadas; mientras que la empresa de transportes de Antonio requiere sobre todo know how en logística y contaduría. En ambos casos, las estrategias sucesoras cuentan con hijos que han sido perfilados para heredar las empresas (de los primeros matrimonios).

En el análisis cuantitativo, la elite cuenta con una alta proporción de jefatura masculina, pero se observan algunas diferencias en los cónyuges de la clase alta dominante, quienes superan en nivel de estudios a los respectivos referentes de hogar (universitario completo). Esto podría sugerir que los referentes de la elite no dependen tanto del capital escolar para posicionarse, en tanto sus cónyuges sí requieren elevada escolaridad, atributo que posiblemente sea eficaz en el mercado matrimonial.

\section{CLASE MEDIA ESTABLECIDA}

Su composición sería para 2011 de un 29\%, siendo relevante en su configuración el tipo de hogares (pequeños o unipersonales), cuyos referentes son jóvenes y con ingresos fuertemente asociados a niveles medios y altos (ingreso per cápita familiar ubicado entre el $7^{\circ}$ y el $9^{\circ}$ decil). Las ocupaciones de los jefes de hogar se asocian a puestos de técnicos o profesionales, en la condición de empleados asalariados y, en menor medida, de jefes, en las ramas de educación, salud y gestión jurídico-administrativa. Sus inserciones en el mercado de trabajo se vinculan al sector estatal, en establecimientos medianos (de 6 a 40 personas) con cobertura médica, social y laboral (Gutiérrez y Mansilla, 2015). Sus capitales vendrían definidos por lo que Savage et al. (1992) denominan activos culturales y organizacionales (en consonancia con los niveles educativos, de niveles universitario completo $\mathrm{y}$, menormente, 
incompleto). En este sentido, coinciden también con las burocracias de Estado (nacional, provincial y municipal) descritas por Sautu, quien relaciona la capacidad de acumulación de las clases medias en ámbitos estatales con el acceso a ciertas oportunidades y ventajas (aportes jubilatorios, bienes de consumo durable, viviendas) respecto a la clase popular. En las probabilidades de acceder, sostenerse y graduarse en la educación superior (tanto terciaria como universitaria) también se manifiestan las desigualdades entre estas clases (Sautu, 2016). Como han señalado García de Fanelli y Jacinto (2010), a pesar de la expansión de la matrícula de estudios superiores, en Argentina hay una importante brecha cultural entre los diferentes sectores socioeconómicos, que se hace más acentuada en el acceso y finalización de los estudios universitarios que en el terciario (respectivamente, el $40 \%$ y el $25 \%$ tiene padre con educación superior).

Aquí el género marca diferentes fracciones, junto con la edad y la conformación del hogar. Un primer grupo se asocia más a jefatura femenina, con un capital cultural institucionalizado alto (titulación universitaria) y con ocupaciones ligadas a la salud y educación estatales. El otro grupo, en cambio, está fuertemente asociado a la presencia de jefes de hogar jóvenes y solteros, a hogares unipersonales y a calificación técnica. Sus inserciones se vinculan con la gestión administrativa y jurídica. Estas características han sido utilizadas para seleccionar la muestra de entrevistas, cuyos casos figuran en el cuadro 1.

Algunas de las mujeres entrevistadas para la primera fracción de esta clase (Sandra, Luisa) son jefas de hogar con hijos a cargo (separadas). Otras son separadas sin hijos (Lucía) y, por último, hay solteras. De alguna manera, todas estas mujeres han tendido a empequeñecer sus hogares, posiblemente por la dificultad de conciliar ámbitos de producción y reproducción. Todas estas mujeres cuentan con titulaciones universitarias o terciarias completas, y se insertan en el ámbito estatal (salud y educación), lo que supone inversiones sostenidas y constantes en capital cultural (concursos, promociones, titulaciones finalizadas, etc.) que requieren dosis elevadas de inversión temporal por fuera del horario de trabajo. Tener pocos hijos o prescindir de tenerlos se aviene bien con las demandas de esos espacios laborales. Según los resultados del análisis estadístico, esta clase posee una composición de hogares con menos miembros que la clase trabajadora y fundamentalmente con una proporción más baja de menores de 10 años.

En la segunda fracción de esta clase, con jefatura masculina y relativamente más 
joven, prima la relación con estudios universitarios incompletos o terciarios y con hogares unipersonales o de reciente formación - seguramente, ambas características se relacionan a su vez con los grupos de edad -. Encontramos un caso de una cónyuge que estaba embarazada al momento de la entrevista, esperando su primer hijo. Jorgelina (26 años) es hija de odontólogos y con una fuerte presión por terminar su carrera de ingeniería. Intuimos que en su caso se presentaba una tensión fuerte entre el mandato familiar de finalizar los estudios, y la oportunidad que relató sobre la valoración de sus conocimientos en una importante fábrica de bebidas donde se ha ido promocionando y desarrollando en los últimos años. Sin embargo, el momento de impase que significaba tener su primer hijo, era tomado como una oportunidad para finalizar sus estudios ${ }^{17}$ (desacelerando el ritmo de trabajo, turnándose con su pareja, que se dedicaría más intensivamente a trabajar en el mismo establecimiento). Estos arreglos familiares son extremadamente complejos, y se dirimen entre legitimidades discursivas múltiples (mandatos maternales y profesionales en colisión, conformidades a papeles relativamente relegados, etc.).

CUADRO 1 - Muestra de entrevistados pertenecientes a las clases y fracciones de clase de Gran Córdoba.

\begin{tabular}{|c|c|c|c|}
\hline Clase & Fracción & Entrevistado & Descripción \\
\hline \multirow{5}{*}{ 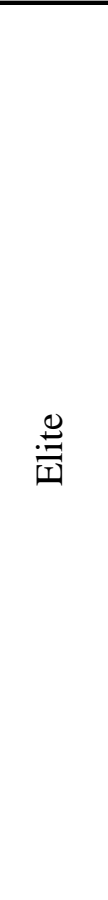 } & \multirow[t]{5}{*}{$1^{\circ}$ Fracción } & Ricardo & $\begin{array}{l}\text { Investigador de CONICET, } 61 \text { años. } \\
\text { Universitario y doctorado. Referente de } \\
\text { hogar y Cónyuge (universitario completo). } \\
\text { Dos hijos emancipados (31 y 28). }\end{array}$ \\
\hline & & Silvana & $\begin{array}{l}\text { Camarista, } 60 \text { años. Universitario y } \\
\text { posgrado. Referente de hogar, cónyuge } \\
\text { jubilado (universitario completo) y dos hijos } \\
\text { (32 y 30). Un hijo emancipado (34). }\end{array}$ \\
\hline & & Federico & $\begin{array}{l}\text { Director institución educativa y docente, } 52 \\
\text { años. Universitario y posgrado. Referente de } \\
\text { hogar de cuatro miembros: cónyuge ( } 52 \text {, } \\
\text { universitario completo y posgrado) y dos } \\
\text { hijos ( } 20 \text { y 14). }\end{array}$ \\
\hline & & José & $\begin{array}{l}\text { Prosecretario de Justicia, } 46 \text { años. } \\
\text { Universitario y posgrado. Referente de hogar } \\
\text { de cinco miembros: cónyuge ( } 44 \text {, } \\
\text { universitario completo) y tres hijas }(14,11 \text { y } \\
\text { 8) }\end{array}$ \\
\hline & & Andrea & $\begin{array}{l}\text { Directora instituto terciario, } 58 \text { años. } \\
\text { Universitario y posgrado. Referente de hogar }\end{array}$ \\
\hline
\end{tabular}

\footnotetext{
17 Mancini (2007) registró en una investigación este tipo de tensiones, en las que el "nuevo" mandato profesional de las clases medias choca con el "viejo" mandato maternal, recurriendo en ocasiones las mujeres a subterfugios de legitimidad en los estudios para poder permanecer los primeros años de crianza de los hijos en el ámbito doméstico.
} 


\begin{tabular}{|c|c|c|c|}
\hline & & & unipersonal. \\
\hline & & Magdalena & $\begin{array}{l}\text { Asesora técnica de Agencia de Promoción de } \\
\text { Empleo, } 57 \text { años. Universitario y Posgrado. } \\
\text { Referente de hogar unipersonal y sostén de } \\
\text { hogar de } 3 \text { hijos (30,28 y 26). Un hijo } \\
\text { residiendo en China (32). Separada } \\
\text { (exmarido: universitario completo). }\end{array}$ \\
\hline & $2^{\circ}$ Fracción & Mariano & $\begin{array}{l}\text { Dueño de Consultora, } 55 \text { años. Universitario } \\
\text { y posgrado. Referente de hogar de dos } \\
\text { miembros. Cónyuge (universitario } \\
\text { completo). Segundo matrimonio. }\end{array}$ \\
\hline & & Antonio & $\begin{array}{l}\text { Dueño empresa transportes, } 65 \text { años. } \\
\text { Universitario incompleto. Referente de hogar } \\
\text { de tres miembros: cónyuge (53, universitario } \\
\text { completo) e hijo (11). Segundo matrimonio. }\end{array}$ \\
\hline & $1^{\circ}$ Fracción & Lucía & $\begin{array}{l}\text { Médica en hospitales públicos y privados, } 30 \\
\text { años. Universitario y posgrado. Referente de } \\
\text { hogar unipersonal. Separada (exmarido: } \\
\text { universitario incompleto) }\end{array}$ \\
\hline & & Viviana & $\begin{array}{l}\text { Empleada pública, } 43 \text { años. Universitario y } \\
\text { posgrado. Referente de hogar unipersonal. }\end{array}$ \\
\hline & & Luisa & $\begin{array}{l}\text { Médica en hospital público, } 54 \text { años. } \\
\text { Universitario completo. Referente de hogar: } \\
\text { dos hijas ( } 20 \text { y 18). Separada (exmarido: } \\
\text { secundario incompleto). }\end{array}$ \\
\hline & & Sandra & $\begin{array}{l}\text { Docente primario y preceptora, } 49 \text { años. } \\
\text { Terciario completo. Referente de hogar: dos } \\
\text { hijas }(26 \text { y } 24) \text {. Separada (exmarido: } \\
\text { secundario completo) }\end{array}$ \\
\hline$\frac{\pi}{0}$ & & Adriana & $\begin{array}{l}\text { Vicedirectora escuela secundaria, } 57 \text { años. } \\
\text { Universitario completo. Referente de hogar } \\
\text { unipersonal. }\end{array}$ \\
\hline 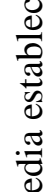 & $2^{\circ}$ Fracción & Gerardo & $\begin{array}{l}\text { Programador de empresa informática, } 41 \\
\text { años. Universitario incompleto. Referente de } \\
\text { hogar. Cónyuge masculino (58, universitario } \\
\text { incompleto). }\end{array}$ \\
\hline$\sum^{0}$ & & Nahuel & $\begin{array}{l}\text { Empleado administrativo empresa gas, } 25 \\
\text { años. Universitario incompleto. Referente de } \\
\text { hogar unipersonal. }\end{array}$ \\
\hline & & Iris & $\begin{array}{l}\text { Empleada pública, } 36 \text { años. Universitario } \\
\text { Incompleto. Cónyuge de hogar de dos } \\
\text { miembros (referente } 32 \text {, universitario } \\
\text { completo y doctorado). }\end{array}$ \\
\hline & & Jorgelina & $\begin{array}{l}\text { Empleada empresa bebidas, } 26 \text { años. } \\
\text { Universitario Incompleto, cónyuge de hogar } \\
\text { de dos miembros (referente 26, universitario } \\
\text { completo). }\end{array}$ \\
\hline & & Flavio & $\begin{array}{l}\text { Gerente empresa familiar, } 32 \text { años. } \\
\text { Universitario incompleto. Referente de hogar } \\
\text { de dos miembros (cónyuge: } 31 \text {, universitario } \\
\text { completo). }\end{array}$ \\
\hline & & Pedro & $\begin{array}{l}\text { Preceptor, } 32 \text { años. Terciario incompleto. } \\
\text { Referente de hogar unipersonal }\end{array}$ \\
\hline
\end{tabular}




\begin{tabular}{|c|c|c|c|}
\hline & & Dante & $\begin{array}{l}\text { Empleado, } 32 \text { años. } \quad \text { Universitario } \\
\text { incompleto. Referente de hogar unipersonal }\end{array}$ \\
\hline & & Enrique & $\begin{array}{l}\text { Vendedor inmobiliario y martillero, } 33 \text { años. } \\
\text { Terciario completo. Referente de hogar de } \\
2 / 3 \text { miembros: cónyuge ( } 32 \text {, universitario } \\
\text { completo) e hijo ( } 6 \text { años, custodia } \\
\text { compartida). Segunda unión. }\end{array}$ \\
\hline \multirow{11}{*}{ 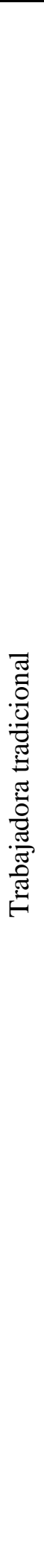 } & \multirow[t]{6}{*}{$1^{\circ}$ Fracción } & Milo & $\begin{array}{l}\text { Taxista, } 61 \text { años. Secundario Completo. } \\
\text { Referente de hogar de dos miembros: } \\
\text { cónyuge (58, secundario completo) y tres } \\
\text { hijos emancipados }(34,32 \text { y } 31) \text {. }\end{array}$ \\
\hline & & Laura & $\begin{array}{l}\text { Panadera, } 64 \text { años. Secundario completo más } \\
\text { cursos. Referente de hogar de dos miembros: } \\
\text { cónyuge ( } 66 \text {, secundario completo). Dos } \\
\text { hijos emancipados ( } 36 \text { y } 33 \text { ). }\end{array}$ \\
\hline & & Alberto & $\begin{array}{l}\text { Camionero, } 55 \text { años. Secundario incompleto. } \\
\text { Referente de hogar de tres miembros: } \\
\text { cónyuge (55, secundario completo más } \\
\text { cursos) e hijo (27). Dos hijos emancipados } \\
(32 \text { y 29). }\end{array}$ \\
\hline & & Oscar & $\begin{array}{l}\text { Jardinero, } 64 \text { años. Secundario incompleto. } \\
\text { Referente de hogar de dos miembros } \\
\text { (cónyuge, primario completo). } 5 \text { hijos } \\
\text { emancipados. }\end{array}$ \\
\hline & & Eduardo & $\begin{array}{l}\text { Mecánico autónomo, } 60 \text { años. Secundario } \\
\text { incompleto. Referente de hogar de tres } \\
\text { miembros: cónyuge ( } 49 \text {, secundario } \\
\text { completo) e hija (10). Segundo matrimonio. }\end{array}$ \\
\hline & & Iván & 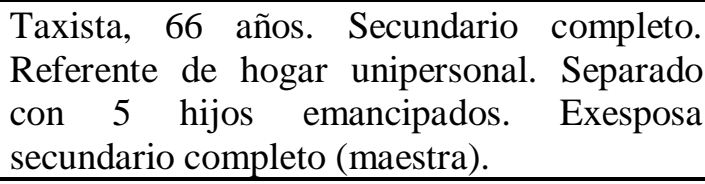 \\
\hline & \multirow[t]{5}{*}{$2^{\circ}$ Fracción } & Carina & $\begin{array}{l}\text { Operaria fábrica autopartes, } 43 \text { años. } \\
\text { Universitario incompleto. Referente de hogar } \\
\text { (tres hijas: 19, 12, 11). Viuda (cónyuge } \\
\text { fallecido: secundario incompleto). }\end{array}$ \\
\hline & & Matías & $\begin{array}{l}\text { Empleado en una sandwichería, } 43 \text { años. } \\
\text { Universitario incompleto. Referente de } \\
\text { hogar. Cónyuge ( } 37 \text {, secundario completo } \\
\text { más cursos) e hijos ( } 16,8 \text { y } 5 \text { ). }\end{array}$ \\
\hline & & Marina & $\begin{array}{l}\text { Ama de casa, } 26 \text { años. Universitario } \\
\text { incompleto. Cónyuge de hogar con referente } \\
\text { de } 34 \text { años, terciario incompleto, empleado } \\
\text { fábrica de cerámicos. Dos hijos ( } 2 \text { años y } 2 \\
\text { meses). }\end{array}$ \\
\hline & & Fermín & $\begin{array}{l}\text { Operario fábrica automotriz, } 43 \text { años. } \\
\text { Secundario completo. Referente de hogar: } \\
\text { cónyuge ( } 44 \text {, secundario completo más } \\
\text { cursos), dos hijos ( } 11 \text { y } 9 \text {, de ella). Segundo } \\
\text { matrimonio. Dos hijas del primero no } \\
\text { convivientes ( } 25 \text { y } 23) \text {. }\end{array}$ \\
\hline & & Adam & $\begin{array}{l}\text { Chofer de empresa transporte urbano, } 31 \\
\text { años. Terciario incompleto. Referente de } \\
\text { hogar. Cónyuge ( } 32 \text {, terciario completo) y } 3\end{array}$ \\
\hline
\end{tabular}




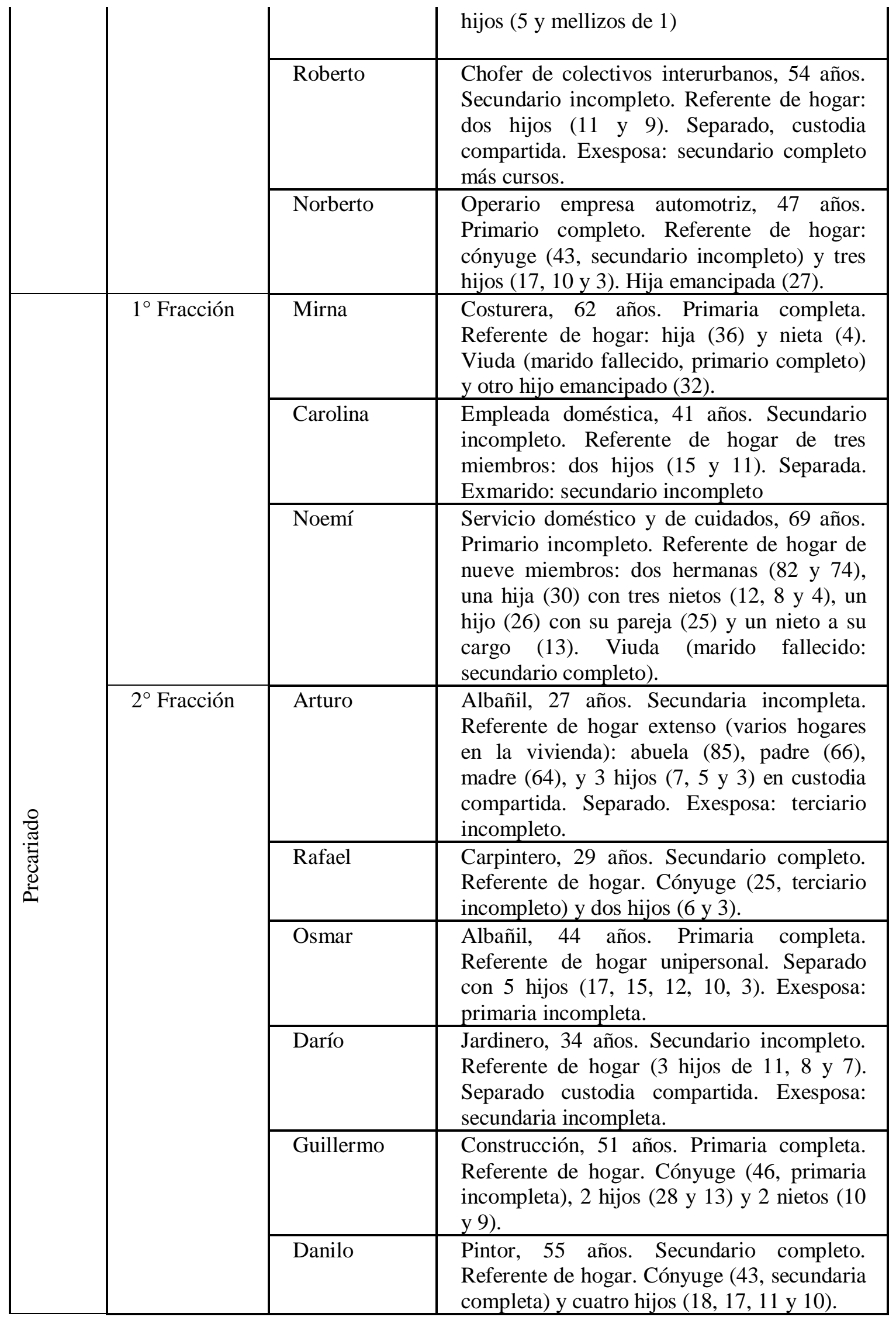

Elaboración propia. 


\section{CLASE TRABAJADORA TRADICIONAL}

Compuesta por aproximadamente el 35\% de los hogares del espacio social, se definen por tener ingresos medios y bajos $\left(3^{\circ}\right.$ a $5^{\circ}$ decil si se toma el ingreso per cápita familiar, pero llegando hasta el $8^{\circ}$ decil si se considera el ingreso de la ocupación principal del referente de hogar). Sus referentes se insertan en las ramas de la construcción, la industria, el transporte y la logística, en condición de autónomos y en establecimientos pequeños del sector privado. La clase se caracteriza, además, por una fuerte asociación a situaciones conyugales (unidos o casados), a configuraciones familiares con 4 o más miembros y una alta presencia de menores de 10 años. Esto se relaciona con las altas tasas de dependencia identificadas por Perona y Schiavoni (2018), características en los hogares conformados por obreros. El capital escolar de sus referentes tiende a ser bajo (el nivel educativo va de primario incompleto a secundario incompleto), más aún si se toma como referencia los niveles educativos de la clase media.

En esta clase el procedimiento de clasificación no generó dos fracciones tan nítidas. Sin embargo, fue posible identificar dos grupos vinculados a la edad y las ramas de ocupación del referente de hogar. El primero, se asocia a referentes de mayor edad (más de 50 años) vinculados al cuentapropismo y a la logística desde hace más de cinco años. La segunda se compone por referentes más jóvenes (entre 35 a 50 años) vinculados a la industria y con hogares numerosos (Gutiérrez y Mansilla, 2015).

En el trabajo cualitativo, encontramos casos de jefatura masculina (a excepción de Laura, quien convive con su marido jubilado, antiguo operario) que se han insertado en fábricas vinculadas a la industria automotriz y metalmecánica durante muchos años y luego fueron despedidos en ciclos de retraimiento, virando hacia actividades más informales (conducción de taxi, jardinería, pintura). Otros se iniciaron como choferes de transporte público o privado (camiones, colectivos de larga o corta distancia), persistiendo actualmente en la actividad. Estos trabajos masculinos (con uso extensivo del tiempo en el espacio laboral) se complementan con una sostenida presencia en el hogar de mujeres amas de casa o trabajadoras en servicio doméstico ocasionales, pues la intensidad horaria de referentes (turnos rotativos en fábricas, régimen de transportistas, etc.) dificultan la disponibilidad de tiempo para la inserción laboral de ellas. Asimismo, abunda la referencia de las mujeres a capacitaciones en formato de cursos (tejidos, manualidades, tarjetería) que se aplican para generar alguna actividad 
económica esporádica, o para ahorrar en contratación de servicios para la familia hacer tarjetas para las comuniones, repostería para cumpleaños y para vender, etc.-. Las inversiones temporales en tareas domésticas - y la esporádica e intermitente inserción en el mercado laboral - entre las mujeres de esta clase, se comprende por la mayor presencia de integrantes menores de 10 años en estas familias y el carácter más numeroso de sus hogares ${ }^{18}$. Lola, la esposa de Alberto (camionero), y quien tiene secundario completo (escuela privada confesional) relata la constante vigilancia que tuvo sobre el rendimiento escolar de los hijos: búsqueda permanente de la escuela adecuada y control sobre la justicia de las notas de calificación.

En tanto, el grupo más joven, al transitar por una fase de expansión del ciclo familiar implica una mayor intensificación de las tareas de cuidado de los hijos (más pequeños) por parte de las mujeres cónyuges, quienes son mayormente amas de casa. A su vez, los referentes de esta fracción tienen inserciones más heterogéneas (transporte, empleados y también obreros). Amén de los contextos históricos diferentes de cada grupo de edad, podría pensarse también que estos referentes se insertan en las industrias en la fase del ciclo vital en que son más productivos para las empresas. Algo que, dada la intensidad de las tareas y horarios, se apoya en el trabajo doméstico de las cónyuges para la organización familiar.

\section{PRECARIADO (CLASE BAJA)}

Conformada por aproximadamente el $20 \%$ de los hogares de Gran Córdoba, es una de las regiones del espacio social - junto con la clase media - en la que el género particiona dos grupos bien diferenciados. Una de las fracciones cuenta con gran asociación al género femenino, con el $80 \%$ de los referentes de hogar mujeres, que se asocian también a situación de divorciadas o viudas, sin calificación laboral y que se desempeñan en el servicio doméstico. El otro grupo queda constituido por un $12 \%$ de los hogares con referente masculino, vinculado a actividades de construcción y cuentapropismo, con calificación operativa y que residen en hogares numerosos. En ambas fracciones, los referentes tienen ingresos y niveles educativos más bajos que el

\footnotetext{
${ }^{18}$ Como señalan Faur y Pereyra (2018), la impronta maternalista para realizar las tareas de cuidado hacia la infancia en Argentina es muy fuerte. No obstante, la externalización de este servicio a instituciones estatales o privadas queda encomendado a importantes disparidades regionales y de clase social (en el caso de servicios privados, que son mayoritarios). Incluso la percepción del déficit de cobertura sobre este servicio constituye una barrera en los estratos más bajos, que no contemplan la provisión del cuidado fuera del ámbito familiar (datos analizados por las autoras de la encuesta ENES-PISAC).
} 
resto de las clases $\left(1^{\circ}\right.$ a $2^{\circ}$ deciles de ingresos, nivel educativo primario incompleto a completo; Gutiérrez y Mansilla, 2015).

En los hogares con jefatura masculina es frecuente que las cónyuges tengan más capital cultural que los varones. Es el caso de la familia de Rafael, quien tiene secundario completo mientras su cónyuge estudia enfermería en un terciario, y vuelcan sobre los hijos las expectativas de mejorar sus opciones educativas (búsqueda de banco en escuelas públicas prestigiosas, a través de contactos). Y como pudimos observar en las entrevistas, es algo que parece tener algún efecto incluso en casos de separación, traccionando las opciones educativas de los hijos hacia los lugares apreciados como mejores. Por ejemplo, el caso de Arturo, quien no terminó la secundaria, sin embargo, su exesposa finalizó estudios medios en un colegio nocturno para mejorar sus posibilidades laborales. En esta familia hay una serie de apuestas económicas para buscar un colegio que consideran mejor para sus hijos (pago de colegios privados, aún a riesgo de perder el derecho a la $\mathrm{AUH})$.

Este tipo de prácticas desborda el papel economicista de la ocupación laboral como único lugar donde se ejercita la titulación, y proporciona una invitación a sostener una mirada integral sobre las diferentes estrategias de reproducción social entramadas, en las que interviene el capital cultural de los miembros de la familia en múltiples sentidos.

\section{EDUCACIÓN Y GÉNERO: ¿DIFERENTES RETORNOS?}

Intentaremos esbozar en este apartado algunas conjeturas acerca de los modos en que puede ser valorizado y reconocido el capital cultural en términos de desigualdad social por género, considerando la relación entre ámbitos doméstico (reproductivo) y extradoméstico (productivo). Esto desbordaría las habituales concepciones sobre el retorno educativo, cuyas premisas interpretan que, a una determinada inversión para lograr titulaciones, es esperable cierta recompensa económica (salario en el mercado laboral) - en términos de reconocimiento al esfuerzo, pilar de las sociedades meritocráticas -. Consideramos la noción de "retorno educativo" como deficitaria, entre otras cosas, porque homogeneiza formatos de inserción laboral, lógicas y tiempos de valorización en segmentos del mercado de trabajo profundamente disímiles para las distintas posiciones del espacio social. Además, otorga pocas herramientas para dar cuenta de intereses extra-económicos de las prácticas: como son las inversiones 
escolares y el conjunto de sentidos con el que se significan y justifican estrategias (como las educativas, formativas, de crianza y socialización) que consumen buena parte de las energías y los recursos familiares, sin ofrecer "retornos" inmediatamente observables (Assusa y Jiménez, 2017).

Ahora bien, muchas investigaciones han resaltado que el nivel de estudios es uno de los principales factores de la mayor igualdad de género en la familia (Badinter, 1980; South y Spitze, 1994; Ferrand, 2004; Baudelot y Leclercq, 2005), además de propiciar la participación femenina en el mercado laboral (Hartmann, 1981; Gómez Bueno, 2001; Jurado, 2005). Aquí pretendemos orientar la mirada hacia otras zonas de la vida social, como la doméstica, para interpretar si hay otras utilidades del capital cultural: ¿cómo circula en el mercado matrimonial? ¿qué ponderación tiene de cara a las estrategias de reproducción social y de organización doméstica? ¿constituye un factor de "empoderamiento" de las mujeres, aunque no se valorice en el mercado de trabajo?

Repasaremos brevemente cómo se compone cada clase social en términos de capital cultural institucionalizado (Bourdieu, 2011). Para el año 2011 los referentes de hogar del clase baja o precariado presentan una fuerte concentración de casos con nivel primario completo (60\%), y en la clase alta, en cambio, están muy representados en el nivel superior universitario completo (más del 70\%). La clase trabajadora se concentra en torno al nivel secundario incompleto $(60 \%)$ y la clase media en el nivel superior universitario incompleto (60\%). Respecto al año 2003, en todas las clases aumentan los niveles educativos (ver gráfico $1^{19}$ ).

\footnotetext{
${ }^{19}$ Las nomenclaturas del gráfico varían ligeramente de las utilizadas en el texto: la clase alta dominante es la elite, la clase media dominante es la clase media, la clase media dominada es la clase trabajadora tradicional, y la clase baja dominada es el precariado.
} 
GRÁFICO 1 - Nivel educativo de los referentes de hogar por clase.

Gran Córdoba (2003-2011)

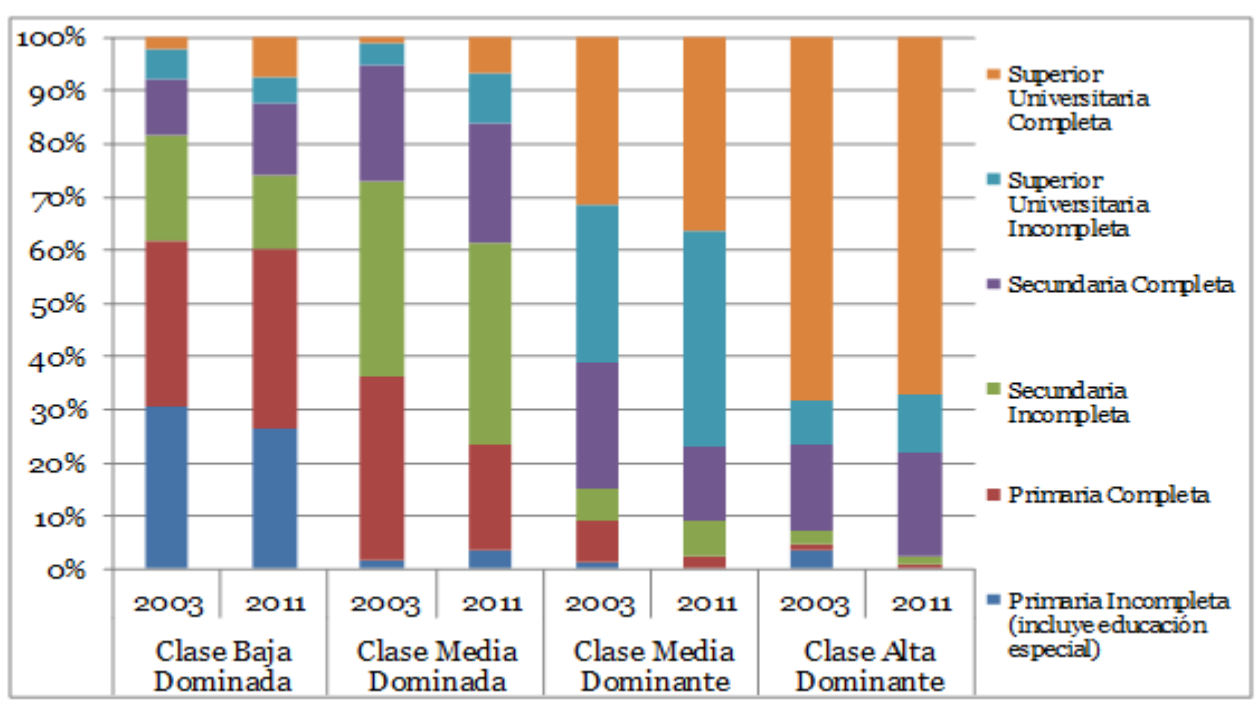

Fuente: elaboración propia con datos de la EPH - INDEC (2003-2011).

Jiménez Zunino y Giovine (2016).

Asimismo, los cónyuges también mejoraron sus credenciales educativas en el periodo 2003-2011, como se observa en el gráfico 2. Los cónyuges presentan características similares en términos educativos a los referentes de hogar (casados o unidos), lo que sugiere cierta homogamia educativa entre los referentes de hogar y los cónyuges (considerando solo a quienes conviven en parejas). Así, en los cónyuges del precariado o clase baja se observa más de un 50\% de presencia en el nivel primario, en tanto para la clase alta dominante presentan casi un $80 \%$ de frecuencias en nivel universitario (completo e incompleto). En tanto, los cónyuges de la clase trabajadora se concentran, como los referentes, en el nivel secundario (80\%), en tanto los de la clase media tienen mayor presencia que éstos en el nivel superior universitario (60\%). Estos hallazgos están en sintonía con los planteos sobre homogamia educativa (Rodríguez, 2011), pero también sobre cierto aventajamiento de las mujeres en términos de acumulación de credenciales educativas. 
GRÁFICO 2 - Nivel educativo de los cónyuges por clase (2003-2011)

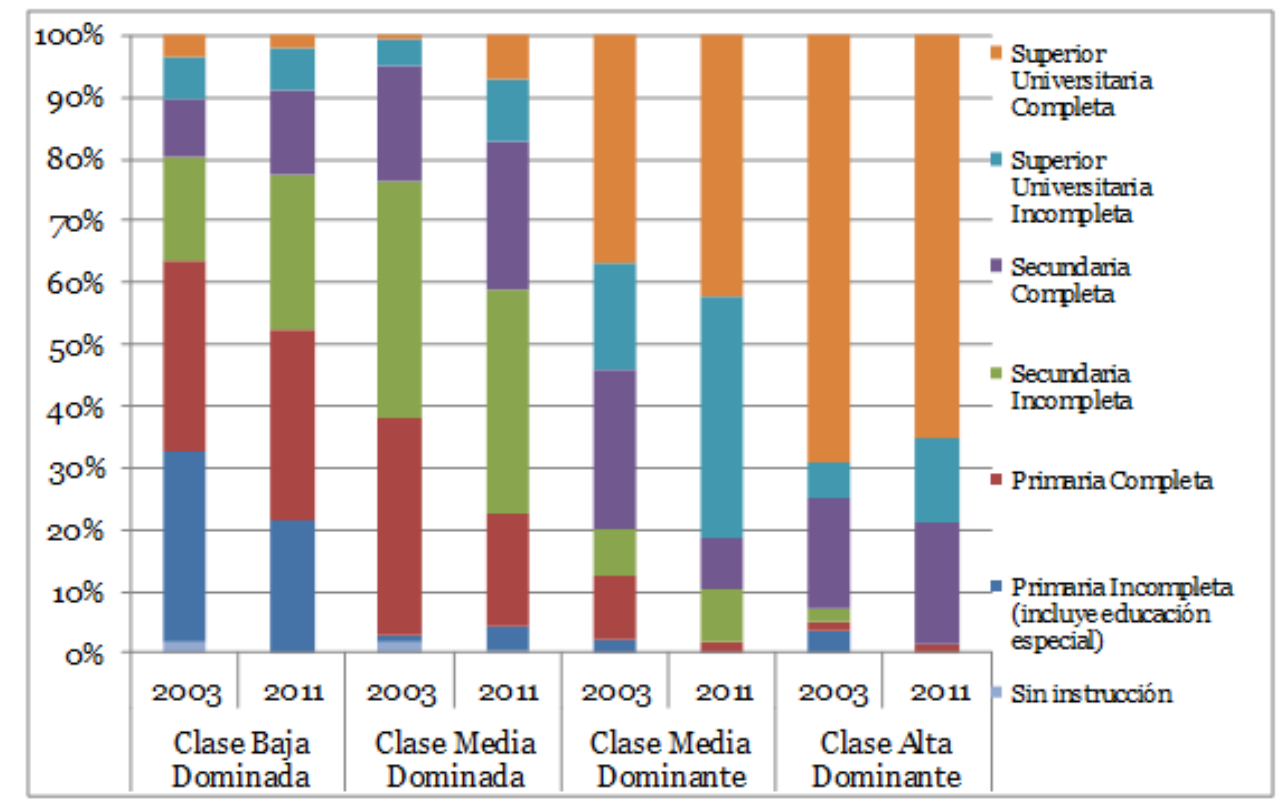

Fuente: elaboración propia con datos de la EPH - INDEC (2003-2011).

Jiménez Zunino y Giovine (2016).

Hay que considerar que el procedimiento de construcción de las clases establecía como uno de los criterios relevantes para dar cuenta de la desigualdad social del nivel educativo alcanzado de los referentes de hogar, y esto puede inducir cierta circularidad en la lectura de estos hallazgos. Sin embargo, al no tratarse de una explicación causal (de una variable sobre otra), sino de la multicausalidad de un conjunto de variables posibilitada por el método utilizado (ACM), intentamos comprender la articulación de las diferentes variables y sus valores (niveles educativos, sexo, posición al interior de los hogares, etc.) para observar las dinámicas vinculadas a las inserciones en el mercado de trabajo y a la organización doméstica.

En este sentido, las teorías que restringen la mirada de los retornos educativos al mercado laboral no posibilitan ver qué otras "utilidades" o lecturas puede hacerse respecto a la posesión de credenciales educativas. Por ejemplo, en análisis que relacionan nivel educativo de referentes de hogar por sexo - no podemos mostrar datos aquí por motivos de espacio, ver Jiménez Zunino y Giovine (2016) -, hemos encontrado una mayor eficiencia en los varones para traducir el capital cultural en el mercado laboral: en variables como calificación ocupacional e ingresos aventajan a las mujeres aún teniendo éstas mayor nivel educativo alcanzado.

La clase alta, como dijimos, casi no cuenta en el recorte muestral que capta la EPH con jefatura de hogar femenina (aunque sí fue buscado en el trabajo cualitativo). 
Sin embargo, las cónyuges superan en titulaciones al referente - en el análisis estadístico -. Lo que nos da indicios de: a) esas posiciones de clase no están tan atadas a la capitalización de títulos como de otros activos (económicos, por ejemplo); y b) la posición de cónyuge al interior de los hogares puede requerir, en esas posiciones sociales, de elevadas credenciales educativas (en el mercado matrimonial).

También la clase trabajadora presenta este patrón de hipogamia educativa: mayores titulaciones de las mujeres que, sin embargo, no se trasladan al mercado de trabajo, por lo que cabe la hipótesis de otras utilidades para la organización doméstica. De hecho, el trabajo cualitativo muestra una función de constante vigilancia sobre la crianza de los hijos, seguimiento en la escuela y en actividades extraescolares que en estas dos clases suele recaer en las mujeres (cónyuges). Vimos para la clase trabajadora la intensidad de las tareas de reproducción y domésticas, al contar sus maridos con trabajos de prolongadas y rotativas jornadas.

Es posible que el capital cultural mayor de las cónyuges constituya una fuente de valorización social al interior de los hogares y en los entramados familiares, al depositar sobre las mujeres el cuidado y crianza. Ello no obsta que en estos hogares las mujeres se encuentren en situaciones de dependencia económica de los jefes de hogar (al no contar con salario propio). Pero la complejidad de las relaciones familiares amerita que no se reduzca a la dimensión económica la trama de intercambios que tienen lugar en los hogares. Es posible pensar, en este sentido, que la hipogamia educativa de las mujeres constituya una situación de relativa ventaja para disputar la autoridad y la participación en las decisiones, a falta de ingresos o ingresos inferiores.

Complementariamente a esto, se puede hipotetizar que el mayor capital cultural de las mujeres pueda tener efecto sobre la división sexual del trabajo al interior de los hogares, así como sobre una atenuación de la desigualdad de género. Un estudio realizado en España sobre participación por género en las tareas domésticas señala que la variable que más incide en una mayor equidad es el nivel educativo de la mujer, sobre todo si trabaja fuera del hogar, pero también siendo esta ama de casa (Meil, 1997).

La clase media, por su parte, presenta una mayor equiparación (homogamia) en los niveles educativos de referentes y cónyuges, lo que puede ser indicador de relaciones de género más equitativas. Siguiendo en un plano hipotético, es pensable que sus posiciones de clase son las que estén más ancladas a las acumulaciones de capital cultural, teniendo en cuenta que ambos cónyuges son importantes en términos de 
ingresos para el grupo familiar

La clase baja o precariado, como vimos, cuenta con una fracción femenina importante, ocupada mayormente en servicios de cuidado y doméstico ( $1^{\circ}$ fracción). En la mayoría de los casos suelen ser hogares monopartenales (viudas o separadas), que sostienen complejas estrategias domésticas para mejorar las opciones educativas de sus descendientes, desde sus recursos menores. En tanto, la fracción masculina $\left(2^{\circ}\right)$ se apoya en la división sexual del trabajo y cuenta con la vigilancia de las mujeres (aunque con desigual éxito en la empresa) para supervisar la sociabilidad y educación de los hijos, similar a lo hallado para la clase trabajadora.

\section{PALABRAS FINALES}

Hemos explorado la configuración de las diferentes clases sociales de Gran Córdoba, atendiendo a la composición de sus capitales, y a algunos rasgos que pudimos identificar como definidores de la posición como jefes de hogar o cónyuges. Somos conscientes del carácter exploratorio del texto, que ha partido de datos que no se construyeron para problematizar la desigualdad de género. Sin embargo, ante la evidencia del efecto de esta variable en la conformación de fracciones de clase, consideramos pertinente comenzar a trazar hipótesis interpretativas que consideren la vinculación entre los ámbitos productivo y reproductivo de las vidas de las familias. Consideramos que esto podría comenzar a enriquecer los análisis sobre desigualdad social, así como dimensionar los aportes de los diferentes pilares que forman parte de las estrategias de reproducción social de los hogares (incluso, aunque aquí no está abordado, el papel de las familias extensas en la provisión de ayudas y cuidados). Esto supone el desafío de ampliar la mirada a las mujeres en los estudios de estratificación social como trabajadoras y también como proveedoras de cuidados no monetarizados en las familias, pero esenciales para la organización doméstica. Sin pretender anclar a las mujeres en estos roles - que pueden ser ocupados indistintamente por cualquier género - consideramos importante comenzar a magnificar el valor de estas actividades "no económicas" que posibilitan el despliegue de las actividades "económicas" y la vida de las familias.

En diálogo con los antecedentes disponibles sobre la desigualdad social (especialmente los elaborados desde los datos de la encuesta ENES-PISAC, así como los clásicos estudios de Torrado), hemos caracterizado las clases sociales de Gran 
Córdoba, combinando datos estadísticos con datos cualitativos producidos en entrevistas en profundidad. La comprensión conjunta del pool de variables con las que trabajamos otorga densidad y complejidad al análisis, y permite elaborar interpretaciones acerca de la vinculación entre ámbitos productivo y reproductivo. Esto nos habilita a problematizar la perspectiva unidimensional en la que se registran los logros educativos desde los retornos económicos, que no contemplan más que el intercambio del capital cultural en el mercado de trabajo por salario.

Asimismo, las situaciones de heterogeneidad y desigualdad social al interior de las familias - específicamente, entre los miembros de la pareja - denotan que la homogamia no constituye el único modo de ensamblarse las familias, y despierta interrogantes sobre los efectos que tiene en la organización y la gestión doméstica y extradoméstica. Una de las vías de exploración para los casos de hipogamia educativa femenina es acerca de los modos en que se valoriza el capital cultural en las relaciones de género, en la gestión doméstica, en la transmisión de los demás capitales y en las disposiciones hacia descendientes.

Somos conscientes de las aristas que se abren desde este estudio exploratorio, que habrá de profundizarse con más dimensiones que las volcadas en el texto, como son las encuestas de uso del tiempo, la división del trabajo doméstico en las familias, el origen de clase de los miembros de la pareja, las estrategias hacia los hijos, las economías afectivas movilizadas, que serán materia de próximos análisis.

\section{REFERENCIA}

Álvarez, Mari-Franci. (2013). Educación en cifras. Nivel inicial y primario en Córdoba: 2002-2010. Córdoba: CEPyD.

Assusa, Gonzalo y Jiménez Zunino, Cecilia Inés. (2017). Familias, retornos educativos y clases sociales. Valorización de capital cultural y estrategias escolares de clase media y clase trabajadora en Córdoba. Obets, 12(2), p. 303-335.

Badinter, Elisabeth. L'Amour en plus. París: Flammarion, 1980.

Baranger, Denis. (2004). Epistemología y metodología en Pierre Bourdieu. Buenos Aires: Prometeo.

Barrancos, Dora. (2012). Mujeres en la sociedad argentina. Una historia de cinco siglos. Buenos Aires: Grupo Editorial Argentina.

Baudelot, Christian et Leclercq, François. (2005). Les effets de l'éducation: rapport à 
l'intention du PIREF [Programme incitatif de recherche en éducation et formation (France). Paris : La Documentation française.

Benza, Gabriela y HEREDIA, Mariana. (2012). La desigualdad desde arriba: Ejercicio de reconstrucción de las posiciones sociales más altas en Buenos Aires, VII Jornadas de Sociología de la Universidad Nacional de La Plata La Plata. Recuperado em 5-7 de diciembre de http://jornadassociologia.fahce.unlp.edu.ar.

Bertaux, Daniel y Thompson, Paul. (2009). Introduction. Pathways to Social Class: a qualitative aproach to social mobility. Transaction Publishers: New Brunswick, New Jersey.

Binstock, Georgina. Cambios en la formación de la familia en Argentina: ¿cuestión de tiempo o cuestión de forma?, X Jornadas Argentinas de Estudios de Población, Asociación de Estudios de Población de la Argentina, San Fernando del Valle de Catamarca, Recuperado em 4 a 6 de noviembre de 2009 en https://www.aacademica.org/000-058/25.pdf.

Binstock, Georgina. (2018). Hogares y organización familiar. In J. I. Piovani, y A. Salvia. La Argentina en el siglo XXI. Cómo somos, vivimos y convivimos en una sociedad desigual. Buenos Aires: Editorial Siglo XXI, 421-442.

Bourdieu, Pierre. (2011). Las estrategias de la reproducción social. Buenos Aires: Siglo XXI.

Bourdieu, Pierre. (1998). La distinción: criterios y bases sociales del gusto. Madrid: Taurus.

Carabaña, Julio. (1993). Educación y estrategias familiares de reproducción. In J.L. G. Medina y G. E. Calvo. Estrategias familiares. Madrid: Alianza, p. 37-47.

Carabaña, Julio. (1994). La constante homogamia educativa. Economía y Sociedad, 11, p. 43-66.

Conde, Rosa. (1982). Familia y cambio social en España. Madrid: CIS.

Crompton, Rosemary. (1997). Clase y estratificación. Una introducción a los debates actuales. Madrid: Tecnos.

Faur, Eleonor y Pereyra Francisca. (2018). Gramáticas el cuidado. In J.I. Piovani y Salvia, Agustín. La Argentina en el siglo XXI. Cómo somos, vivimos y convivimos en una sociedad desigual. Buenos Aires: Editorial Siglo XXI, p. 497-534.

Ferrand, Michèle. (2004). Féminin Masculin. Paris : La Découverte.

García de Fanelli, Ana María y Jacinto, Claudia. (2010). Equidad y educación superior en América Latina: el papel de las carreras terciarias y universitarias. Revista Iberoamericana de Educación Superior, 1, p. 58-75.

García de Fanelli, Ana María. (2005). Universidad, organización e incentivos. Desafío 
de la política de financiamiento frente a la complejidad institucional. Buenos Aires: Miño y Dávila - Fundación OSDE.

Gómez Bueno, Carmen. (2001). Las mujeres y el trabajo: principales ejes de análisis. Papers, 63(64), p. 123-140.

Gómez-Rojas, Gabriela y Riveiro, Manuel. (2014). Hacia una mirada de género en los estudios de movilidad social: interrogantes teórico-metodológicos. Boletín Científico Sapiens Research, 4(1), p. 26-31.

Gómez-Rojas, Gabriela. (2008). Las mujeres en los estudios de estratificación social: una mirada desde la encuesta permanente de hogares. Papeles de Población, 14(57), p. 153-167.

Hartmann, Heidi. (1981). The family as the locus of gender, class, and political struggle. Signs, 6, p. 366-394.

Jiménez Zunino, Cecilia Inés y Giovine, (2003-2011). Manuel. Transformaciones del mercado escolar en el espacio social de Gran Córdoba. In A. Gutierrez y H. Mansilla. (2016). El espacio social de las clases y los instrumentos de reproducción social: Dinámicas del mercado de trabajo, el mercado de las políticas sociales, el mercado escolar y el mercado habitacional. Gran Córdoba, Universidad Nacional de Córdoba, p. 159-216.

Jiménez Zunino, Cecilia Inés y Roquero García, Esperanza. (2016). Los discursos expertos sobre crianza y maternidad: aproximación al caso español, 1950-2010. Arenal, 23(2), p. 321-345.

Jorrat, Jorge. (2008). Exploraciones sobre movilidad de clases en Argentina: 20032004. Documento de Trabajo, Instituto de Investigación Gino Germani: 1-36.

Jurado, Teresa. (2005). Las nuevas familias españolas. In R. González, J.Jesús y R. Miguel. Tres décadas de cambio social en España. Madrid: Alianza.

López-Roldán, Pedro. (1996). La construcción de una tipología de segmentación del mercado de trabajo. Papers, 48, p. 41-58.

Maceira, Verónica. Clases y diferenciación social. In J. I. Piovani, y A. Salvia. La Argentina en el siglo XXI. Cómo somos, vivimos y convivimos en una sociedad desigual. Buenos Aires: Editorial Siglo XXI, 2018, p. 49-86.

Mancini, Inés. (2007). Madres modernas: entre mandatos y libertades. In M. Margulis; M. Urresti y H. Lewin. Familia, hábitat y sexualidad en Buenos Aires. Buenos Aires: Editorial Biblos, p. 189-202.

Mauger, Gérard. (2013 ). "Modos de generación" de las "generaciones sociales". Sociología Histórica, (2), p. 131-151.

Meil, Gerardo. (1997). La redefinición de la división del trabajo doméstico en la nueva familia urbana española. Revista Española de Investigación Sociológica, 80, p. 69-93. 
Meil, Gerardo. (1999). La postmodernización de la familia española. Madrid: Acento.

Perona, Nélida y Schiavoni, Lidia. Estrategias familiares de reproducción social. In P.I. Piovani y A. Salvia. (2018). La Argentina en el siglo XXI. Cómo somos, vivimos y convivimos en una sociedad desigual. Buenos Aires: Editorial Siglo XXI, p. 467-496.

Rodríguez, Santiago (2011). Andrés. Pautas matrimoniales en Argentina a principios del S XXI: un análisis de homogamia/heterogamia educacional. Revista Praxis Sociológica, 15, p. 65-82.

Salido Cortés, Olga. (2001). La movilidad ocupacional de las mujeres en España. Madrid: CIS y Siglo XXI.

Sautu, Ruth. (2016). La formación y la actualidad de la clase media argentina. In G. Kessler. La sociedad argentina hoy. Radiografía de una nueva estructura. Buenos Aires: Siglo XXI, p. 163-183.

Savage, Michael; Barlow, James; Dickens, Peter y Fielding, (1992). Tom. Property, Bureaucracy and Culture. London: Routledge.

South, South y Spitze, Glenna. (1994). Housework in marital and nonmarital households. American Sociological Review, $N^{\circ}$ 59: 327-347.

Terrail, Jean Pierre. (1984). Familles ouvrières, école, destin social (1880-1980). Revue Française de Sociologie, XXV, p. 421-436.

Torrado, Susana. (2003). Historia de la familia en la Argentina moderna (1870-2000). Buenos Aires: Ediciones de la Flor.

Torrado, Susana. (2007). Transición de la nupcialidad. Dinámica del mercado matrimonial. Buenos Aires: Editorial Edhasa, p. 399-438.

Torrado, Susana. (2007).Población y bienestar en la Argentina del primero al segundo Centenario. Una historia social del siglo XX (tomo 1). Buenos Aires: Editorial Edhasa, p. 399-438. 